\title{
QoL in Child LQTS Patients Compared to Cardiac Patients
}

\author{
Elizabeth A. Waldron, M.S. ${ }^{1}$, Stephanie H. Felgoise, Ph.D. ${ }^{1}$, Carmella Tress, M.S. ${ }^{1}$, \\ Katherine Lawrence, Ed.S. ${ }^{1}$, Victoria L. Vetter, M.D. ${ }^{2}$
}

\author{
${ }^{1}$ Philadelphia College of Osteopathic Medicine \& \\ ${ }^{2}$ The Children's Hospital of Philadelphia
}

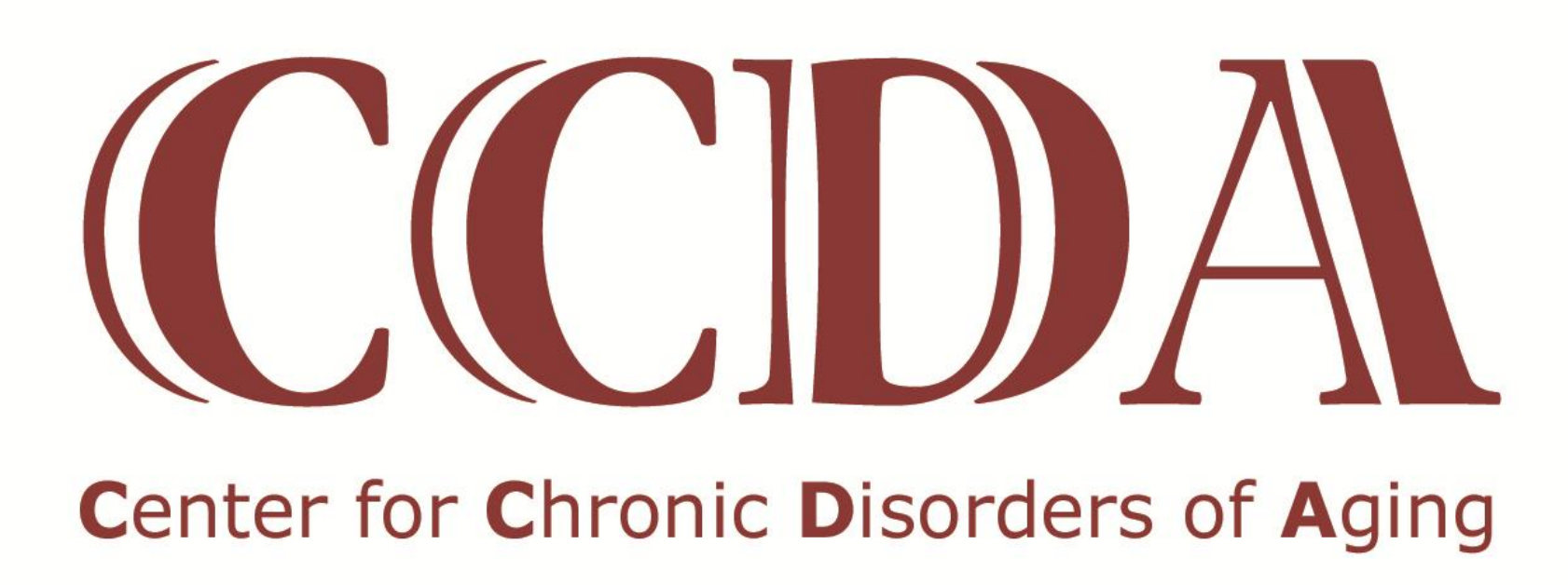

\section{Introduction}

- Long QT Syndrome (LQTS) is a life threatening geneticallyinherited cardiac arrhythmia disorder affecting approximately 1:2500 persons ${ }^{1}$, often diagnosed in childhood.

- Management of LQTS changes patients' lifestyles which can affect quality of life (QoL). Patients have restrictions in physical activity, diet, treatment of noncardiac conditions; take daily doses of medicine and/or have implantable cardiac devices (pacemaker/defibrillator).

- General pediatirc cardiac patients show significantly worse QoL in comparison to healthy controls ${ }^{2,3}$.

- Nearly 1 in 5 with other cardiac disorders reported impaired psychosocial functioning ${ }^{3}$.

- The effects of implanted cardiac rhythm devices in cardiac patients demonstrated a significant effect on QoL in pediatric patient scores ${ }^{4}$.

- LQTS patients are typically not assessed for psychological symptoms.

- Little research on QoL in pediatric LQTS patients has been conducted to determine if psychosocial interventions are warranted.

\section{Methods}

- IRB approval was obtained at both PCOM and CHOP, as part of a larger study.

- Participants: 24 children, $\bar{X}=13.4$ years; $58.3 \%$ female, 95.8\% Caucasian.

- The Cardiac Module of the PedsQoL was given along with other questionnaires measuring psychosocial functioning.

- Measures were completed an average of 5.59 years after receiving the diagnosis of LQTS.

- $39.1 \%$ of participants had been symptomatic since receiving the diagnosis.

- $100 \%$ of the patients are currently taking cardiac medication.

- Z scores were used to compare the dimensional scores for children diagnosed with LQTS to the norms for the Cardiac Module of the PedsQoL ${ }^{4}$

Table 1. Characteristics of LQTS Patients and Normed Group

Age (in years)
$\%$ Female
$\%$ Caucasian
LQTS Patients

$\bar{X}=13.4$
58.3
87.4
Normed Group

Taking Cardiac Medication

Been symptomatic

Time since diagnosis $\quad \bar{X}=5.59$ years unknown
$\bar{X}=9.0$

40

95.8
$31.50 \%$

$39.10 \%$

$\mathrm{n} / \mathrm{a}$

\section{Results}

- No significant differences were found on the Heart

Problems, Physical Appearance, Treatment Anxiety, and

Cognitive Problems Dimensional Scores.

- Communication scores were different and was more of a concern for LQTS patients

Table 2. Differences comparing normed scores and LQTS scores on PedsQL Dimensional Scales

\begin{tabular}{lrrrr}
\hline Dimensional Scale & \multicolumn{1}{c}{$\begin{array}{c}\text { Normed } \\
\text { Score }^{1}\end{array}$} & $\begin{array}{c}\text { LQTS } \\
\text { Patient } \\
\text { Score }\end{array}$ & Z Test & $\boldsymbol{p}$ \\
\hline Heart Problem & 76.02 & 76.09 & 0.0201 & $\mathbf{0 . 4 9 2}$ \\
Physical Appearance & 79.34 & 80.43 & 0.2105 & $\mathbf{0 . 4 1 7}$ \\
Treatment Anxiety & 76.09 & 82.26 & -1.36 & $\mathbf{0 . 0 8 8}$ \\
Cognitive Problems & 75 & 75.66 & -0.157 & $\mathbf{0 . 4 4}$ \\
Communication & 70.65 & 78.84 & $-1.74^{*}$ & 0.041 \\
\hline
\end{tabular}

${ }^{1}$ Normed scores from Varni (2005) ${ }^{*} p \leq .05$

\section{Conclusions}

- Similarities in the QoL scores of general cardiac and LQTS pediatric patients may indicate that similar psychosocial treatment plans may be warranted.

- Pediatric LQTS patients may benefit from a multidisciplinary, biopsychosocial treatment team approach, particularly in addressing the impact that LQTS has on a patient's overall QoL.

- Currently, it is not standard practice for all physicians to offer psychosocial services to patients diagnosed with LQTS $^{6}$ who often present to cardiologists as "well" patients in comparison to other "sick" cardiac patients.

- Barriers may include lack of awareness of the need for referrals for psychosocial services, not having psychologists or therapists available on staff, and lack of awareness of appropriate outside referrals or referral lists ${ }^{6}$.

- Interdisciplinary collaboration between physicians and psychologists may provide a useful service to physicians in addressing the needs and concerns of their patients.

\section{References}

'Schwartz, P.J., Stramba-Badiale, M., Criotti, L., Pedrazzini, M., Besana, A., Bosi, G., Gabbrarini, F., Goulene, K., Insolia, R., Mannarino, S., Mosca, F., Nespoli, L., Rimini, A., Rosati, E., Salice, P., \& Spazzolini, C. (2009) Prevalence of the congenital Long-QT syndrome. Arrhythmia and Electrophysiology, 120, 1761-1767. 2Uzark, K., Jones, K., Burwinle, T.M., \& Varni, J.W. (2003). The Pediatric Quality of Life Inventory in children with heart disease. Progress in Pediatric Cardiology, 18, 141-148.

3Uzark, K., Jones, K., Slusher, J., Limbers, C.A., Burwinkle, T.M., \& Varni, J.W. (2008). Quality of life in children with heart disease as perceived by children and parents. Pediatrics, 121, e1060-1067.

${ }^{4}$ Czosek, R.J., Bonney, W.J., Cassedy, A., Mah, D.Y., Tanel, R.E., Imundo, J.R., Singh, A.K., Cohen, M.I., Miyake, C.Y., Fawley, K., \& Marino, B.S. (2012). Impact of cardiac devices on the quality of life in pediatric patients. Circulation: Arrhythmia and Electrophysiology, 5, 1064-1072.

${ }^{5}$ Varni, J.W., Burwinkle, T.M., \& Seid, M. (2005). The PedsQL as a pediatric patient-reported outcome: Reliability and validity of the PedsQL measurement model in 25,000 children. Expert Review Pharmacoeconomic Outcomes Research, 5, 705-719.

${ }^{6}$ Conlin, E., (2012). "Attention to Psychosocial Concerns Related to LQTS: A Survey of Medical Providers". PCOM Psychology Dissertations. Paper 226. 